\title{
Wittgenstein on the Substance of the World
}

\author{
Ian Proops
}

In the opening pages of the Tractatus, ${ }^{1}$ Wittgenstein presents a striking metaphysics - or metaphysical picture-that seeks to convey a conception of the world as 'the totality of facts'. In the course of these remarks there occurs an argument-or at least the appearance of an argument-for the enigmatic thesis that 'the world has substance':

2.0211 If the world had no substance, then whether a proposition had sense would depend on whether another proposition was true.

2.0212 It would then be impossible to draw up a picture of the world (true or false).

This brief argument has presented an abiding challenge to Wittgenstein's interpreters. One of its many mysteries concerns its invocation of the notion of substance. Because 'objects form the substance of the world' (2.021), the argument must be intended to establish the existence of Tractarian objects. But since that is so, why doesn't Wittgenstein argue directly for objects? Why does he introduce the concept of substance at all?

This question forms the point of departure for the present essay. The answer, I shall claim, is that in portraying objects as comprising the substance of the world' Wittgenstein means to be exploiting the reader's presumed familiarity with the philosophical tradition. Specifically, he is alluding to Kant's conception of substance as that which persists through all existence changes. The allusion, I take it, is intended to convey some (partial and provisional) understanding of the notion of a Tractarian 'object'. The reader who picks up on it will be able to follow Wittgenstein along as he traces the metaphysical picture he intends, later in the book, to undermine.

I shall argue that proceeding on the assumption of a Kantian allusion sheds much light both on the argument for substance itself and on Wittgenstein's socalled 'ontological remarks' at the beginning of the Tractatus. It will emerge that in contending for substance Wittgenstein is arguing not merely for the existence of simple things, but for things that exist necessarily. Moreover, certain (relatively coarse-grained) instabilities and tensions that commentators have discerned in Wittgenstein's talk of 'objects' and 'configurations' will be shown to be resoluble so long as the Kantian background is kept firmly in mind.

In what follows, I will be defending an interpretation according to which Tractarian substance is the modal analogue of Kant's (temporal) notion. Having made this case, I will offer my own interpretation and evaluation of the argument

European Journal of Philosophy 12:1 ISSN 0966-8373 pp. 106-126 (C) Blackwell Publishing Ltd. 2004. 9600 Garsington Road, Oxford OX4 2DQ, UK, and 350 Main Street, Malden, MA 02148, USA. 
for substance at 2.0211-2. My aim will be to see how far it is possible to go towards a sympathetic reconstruction of the argument, while acknowledging that the thesis it is an argument for is intended to be recognized, ultimately, as nonsense (cf. 4.1272, 6.54). Accordingly, as is standard, I shall temporarily adopt the stance of treating Wittgenstein's remarks as making full sense in order to work through the argument on its own (apparent) terms. ${ }^{2}$ But my aim will be limited to understanding Wittgenstein's conception of substance and to reconstructing his (apparent) argument for it. I shall reserve a treatment of the important question of the purpose of Tractarian nonsense for another occasion. ${ }^{3}$

\section{Substance}

Although commentators generally accept that Wittgenstein's talk of substance at $2.0211 \mathrm{ff}$ alludes to some aspect of the philosophical tradition, the target of this allusion is not easy to pin down. What are perhaps the two most widely known conceptions of substance-Aristotle's conception of primary substance in the Categories and Locke's conception of substance in the Essay-turn out to be unlikely candidates. ${ }^{4}$ According to the Categories, substance 'in the truest and primary and most definite sense of the word' is that which is neither 'said of' nor 'present in' a subject, where to be 'present in' a subject is to be incapable of existing apart from it. ${ }^{5}$ So individual men and horses, for example, count as examples of Aristotelian primary substance. ${ }^{6}$

Might Tractarian objects, which constitute the substance of the world (2.021), count as Aristotelian primary substances, and so, with some license, be collectively termed 'substance', in virtue of their independence from other things? This seems unlikely, for Aristotelian individual substances are compound in two respects: they are composites of matter and form, and they have spatial parts. Tractarian objects, by contrast, are in no way compound (zusammengesetzt), and this feature of them is supposed to follow from their forming the substance of the world (2.021).

It is scarcely more credible that Wittgenstein is alluding to another well known conception of substance, namely, the idea-traditionally (if dubiously ${ }^{7}$ ) attributed to Locke- of a substance as an 'entity unknowable in principle, a bare and entirely indeterminate subject of attributes'. ${ }^{8}$ For although Wittgenstein cannot give an example of an object, he does not think that objects are in principle unknowable. Indeed, he was later to say that 'Russell and [he] both expected to find the first elements, or "individuals" ... by logical analysis'. ${ }^{9}$ It seems likely that Wittgenstein is thinking of the 'first elements' as knowable, in principle, by acquaintance. One would know them immediately if one could grasp propositions in their fully analysed forms. This idea would certainly fit with Russell's view that 'this' and 'that' (and, at one stage, 'I') are the only genuine proper names, and also with Wittgenstein's use of the verb 'kennen' in discussing knowledge of objects (cf. 2.0122-3).

(C) Blackwell Publishing Ltd. 2004 
A more plausible conjecture as to the target of Wittgenstein's allusion is Robert Fogelin's suggestion that Wittgenstein is invoking the Kantian conception of substance as 'that which remains unchanged through all changes' ${ }^{10}$ For, like Wittgenstein, Kant usually treats 'substance' as a mass term, and, as we shall see, there is undeniably a connection between Tractarian substance and the notion of a centre of change. However, while Fogelin's observation is broadly sound, it needs to be handled with care. In particular, as we shall see, it is important to keep in mind that the notion of 'change' relevant here is a quite specific one that should not be confused with what Kant means by 'alteration'. That said, I think there is much to be gained by exploring the consequences of supposing Wittgenstein's allusion to be Kantian. I shall argue that doing so enables us to make sense of many Tractarian claims that might otherwise seem almost wilfully obscure, and especially his claim at 2.025 that '[substance] is form and content'.

To understand Wittgenstein's Kantian allusion, it is necessary to consider how the concept of substance figures in the a priori synthetic principle of the Critique of Pure Reason's 'First Analogy' — the so-called 'principle of persistence'. In turn, a prerequisite to understanding this principle is to grasp Kant's distinction between two varieties of change: alteration [Veränderung], on the one hand, and existence change [Wechsel], on the other. The former is a change in which a thing takes on a new 'determination' (a property or configuration) and loses an old one (A187/B230), while the latter is a change in which a thing or a property comes to be or ceases to exist. So, for example, when a tomato turns from green to red upon ripening it undergoes an alteration. But when a piece of wood turns to smoke and ashes upon complete combustion it undergoes an existence change (A 185/B228). Moreover, the particularized colours-or 'tropes' in contemporary parlancethat successively inhere in the ripening tomato themselves undergo existence changes: the greenness of the tomato ceases to be and its redness originates (cf. A 188/B231).

This distinction between two kinds of change is important because Kant's principle of persistence pertains specifically to existence changes. In its secondedition formulation, which is the clearer of the two, the principle runs:

In all change [Wechsel] of appearances substance [Substanz] persists, and its quantum is neither increased nor diminished in nature. (B 224-5)

The concept of 'substance' spoken of here is not Kant's 'category' of substance, which is just the notion from Aristotle's Categories mentioned earlier (A 242-31/ B $300)$, but rather the concept that results from its 'schematization' or connection with time, namely, the concept of 'the persistence of the real in time' (A144/ B183). By 'persistence' Kant means 'existence at all times' (A 242/B 300). So, when he says that substance 'persists in all change [Wechsel]', he means that every existence-change is underlain by-or, in the case of tropes, accompanied bysomething permanent, not that every existence-change is underlain (or accompanied) by something that merely survives the change. Substance, in short, 'endures [bleibt] while everything else changes [wechselt]' (A 144/B 183).

(c) Blackwell Publishing Ltd. 2004 
Drawing these points together, we may gloss the principle of persistence as follows:

\section{Kant's principle of persistence:}

There is some stuff such that every existence change is an alteration of it. ${ }^{11}$

This Kantian background is relevant to our understanding of Wittgenstein for, as we shall see, Tractarian substance is plausibly construed as that which endures through all existence changes of a special, metaphorical kind: 'existence changes' not over time, but through a space of possible worlds.

But before making this case, it is worth pausing to consider how well acquainted Wittgenstein would have been with this Kantian conception of substance. This is not an easy question to settle. We know that Wittgenstein read the first Critique in his prisoner of war camp sometime after November 1918, but it is difficult to find hard evidence that he read it prior to completing the Tractatus in the summer of that year. Indeed, the only remark that might be a reference to the first Critique in the pre-Tractatus manuscripts is the Notebooks' mention of Kant's well-known question 'How is pure mathematics possible?' (19 Oct 1914, Wittgenstein 1979: 15), but, obviously, a person with Wittgenstein's education need not have read the first Critique to have gathered that Kant had concerned himself with this question. On the other hand, there is some evidence that before completing the Tractatus Wittgenstein would have read Kant's Prolegomena to any Future Metaphysics. ${ }^{12}$ For in his only reference to Kant in the Tractatus, Wittgenstein mentions a problem discussed in the Prolegomena but absent from the first Critique, namely, the problem of incongruent counterparts. Moreover, he presents this problem in terms that closely follow Kant's discussion in Prolegomena $\S 13$ and which differ in major ways from his discussions of incongruent counterparts in other works. ${ }^{13}$

Importantly for our purposes, the Prolegomena contains numerous references to the Kantian conception of substance as that which persists through all existence changes. For example: 'in all that exists the substance persists and only the accidents change [wechseln]' (Ak 4: 368). So it seems likely that the pre-Tractatus Wittgenstein would have been exposed to the Kantian conception of substance at least from the Prolegomena, if not from the first Critique. Of course, this only shows that Kant's notion of substance would have come within Wittgenstein's ken: whether he in fact took the idea directly from Kant, or whether he learned of it from his reading of other figures influenced by Kant must remain a question for further investigation.

\section{Tractarian Substance}

The connection I want to defend between Wittgenstein and Kant on the notion of substance might be put as follows: For Wittgenstein, as for Kant, substance [Substanz] is that which 'endures' through all existence changes. But, wheras for Kant 'endurance' is to be understood as existence at all times (permanence), for

(C) Blackwell Publishing Ltd. 2004 
Wittgenstein, it is to be understood, metaphorically, as existence at all possible worlds. The things that 'make up the substance of the world' (2.021) are therefore necessary existents. Moreover, whereas for Kant the items that undergo existence changes are physical objects and their determinations (or configurations), for Wittgenstein they are, in the first instance, configurations of objects, or 'atomic states of affairs' (Sachverhalte) (2.0272). Wittgenstein's invocation of the idea of substance thus involves a nesting of two metaphors: Tractarian substance, figuratively speaking, 'endures' through a metaphorical 'space' of possible worlds. (Wittgenstein prefers the metaphor of 'logical space' to talk of possible worlds, but I shall assume in what follows that talk of possible worlds is the best way to systematize his various metaphorically presented modal conceptions.)

The connection with Kant is most directly established by the following remarks:

2.021 Objects make up the substance of the world. Therefore they cannot be compound.

2.0271 The object is the fixed, ${ }^{14}$ the existent [das Bestehende]; the configuration is the changing [das Wechselnde], the variable. (Ogden's translation $)^{15}$

I shall be defending the following interpretation of these remarks: Objects, since they comprise the substance of the world, are 'the fixed' or 'the existent' in the sense that they exist at every possible world. They are aptly described as constituting 'substance' because they endure through all metaphorical existence changes of configurations over a 'space' of possible worlds. To claim that substance exists, therefore, is not to claim that there are simples, but rather that there are necessary things. The simplicity of these things follows from their necessary existence: for complexes could always be destroyed through the dissolution of the whole into its parts (2.021). ${ }^{16}$

The correctness of this interpretation may not seem obvious, for 2.021 is explicit only about the simplicity of objects. But my understanding of objects as necessary existents is supported by Wittgenstein's claim that objects constitute the 'form' of the world:

2.022 It is clear that however different from the real one an imagined world may be, it must have something-a form-in common with the real world.

2.023 This fixed form consists of the objects.

Since objects comprise the fixed form of the world, and since this form is what any imagined world shares with the actual world, objects must be those things that exist at every imagined world.

Observe that the notion of 'form' appealed to here is Kantian in spirit. Space, for Kant, counts as a 'form' of intuition because any humanly intuitable world must be three-dimensional and Euclidean. Analogously, for Wittgenstein, actual objects constitute the 'form' of the world because any possible world must

(C) Blackwell Publishing Ltd. 2004 
comprise states of affairs that are configurations of them. Thus the object is said to constitute 'the fixed' at 2.0271 because objects, in virtue of existing at every possible world, constitute the world's fixed form.

Two linguistic observations help to support this reading of 2.0271. First, the verbal noun Wittgenstein uses in connection with the kind of change that configurations undergo is 'das Wechselnde' - the expression Kant reserves for existence change-rather than 'das sich Verändernde' (cf. 2.0271). In the figurative progression from world to world, configurations of objects or states of affairs 'change' not by altering-not, that is to say, by taking on new properties and losing old ones-but rather by coming to be or ceasing to exist. Second, the German phrase at 2.0271 that Ogden renders as 'the existent', namely, 'das Bestehende' is based on a root verb 'bestehen', which means not only 'to be in existence', but also 'to stay, or continue, in existence'. Therefore a translation of 'das Bestehende' as 'the persisting' or 'the enduring' may be tolerated. ${ }^{17}$ Either of these renderings would be superior to Ogden's 'the existent' as a way of capturing the contrast Wittgenstein is trying to draw between das Bestehende, on the one hand, and that which undergoes existence changes, on the other.

So, to sum up: objects are 'the fixed', 'the prevailing', because they exist at every possible world; configurations are the 'changing' because they obtain at some worlds and fail to obtain at others, and so undergo (metaphorical) existence changes in the progression from world to world.

At this point, it would be well to ask how much weight these remarks are supposed to bear. The question is especially pressing in view of the fact that some commentators have suggested that the Tractatus's early ontological remarks are designed to disintegrate or 'dissolve from inside' in a rather immediate and localized way. Warren Goldfarb, for example, has suggested that if we try to follow out some of the logical implications of calling something an object, given where the notion is supposed to be fitting in the theory, then we will get nothing coherent $^{\prime 18}$ As an illustration of this strategy he suggests that the contrast between objects and configurations should be thought of as intended to fall apart as we try to think it through. Thus, in commenting on Tractatus 2.0271, which he renders (standardly, but, as we have seen, controversially) ${ }^{19}$ as: 'Objects are unalterable and subsistent: their configuration is what is changing and unstable', Goldfarb says:

Once the notion of 'changing' is scrutinized, it becomes clear that configurations don't change-configurations of objects are what we express by what Quine calls eternal sentences. So when we think it through, we see that we have no relevant conception of altering, and hence no contrast between objects and configurations, however suggestive the idea seemed at first. Its suggestiveness, its ordinary use, is what pushes us along in the dialectic when we are trying to follow out the logical implications [of calling something an object]. ${ }^{20}$

I will argue that, on the contrary, if we take care to situate Wittgenstein's talk of 'changing' at 2.0271 in the context of his Kantian allusion, it will become clear

(C) Blackwell Publishing Ltd. 2004 
that these remarks present a locally stable position, albeit one presented in metaphorical terms.

Let us concede, for the sake of argument, the plausible, if debatable, assumption that Tractarian 'configurations' are appropriately expressed by time-indexed 'eternal sentences'. ${ }^{21}$ How would it follow from this that the distinction between configurations and objects is merely illusory? Goldfarb does not say exactly, but his words suggest the idea that objects and configurations are supposed to be on a par with respect to change since both are, so to speak, frozen in time, and so unaltering. But this idea embodies a confusion. First, even if the states of affairs in which objects figure are time indexed, it does not follow that objects do not alter. For, what it is for an object to alter is (roughly) for it to have one property at one time, and to lack this property at another. Alteration does not require that the altering object should have an intrinsically dynamical aspectand to suppose that it does is to make a mistake closely similar to the mistake Russell saw Zeno as having made of supposing that the possibility of motion requires a state of change. ${ }^{22}$ Second, and for the present purposes more importantly, although-on the conception of the Tractatus-it may be true for other reasons, that we can have no notion of altering according to which timeindexed states of affairs alter, ${ }^{23}$ this is beside the point. In 2.0271 the contrast between objects and configurations concerns not alteration but existence change [Wechseln]. And because configurations undergo existence changes (from one possible world to another), while objects do not, the distinction between objects and configurations with respect to change remains tenable.

Taking seriously the role of objects as the substance of the world enables us to make sense of much of what Wittgenstein has to say about them. Since objects do not undergo existence changes (from one possible world to another), and since the obtaining of atomic states of affairs is just a matter of the existence of certain configurations of (the actual) objects, it follows that once the objects are determined, what atomic facts are possible is fixed: 'If all objects are given, then thereby all possible atomic states of affairs are also given' (2.0124). It is in this sense that 'Objects contain the possibility of all situations (Sachlage)' (2.014). For Kant, the totality of substance, in virtue of the principle of persistence, imposes a constraint on the future and past character of empirical reality. For Wittgenstein, analogously, 'empirical reality is limited by the totality of objects' (5.5561). (Note that Wittgenstein's employment the Kantian phrase 'empirical reality' here would be difficult to explain if it were not an allusion to Kant.) $)^{24}$

These points help to explain why for Wittgenstein 'form is the possibility of structure' (cf. 2.033). This means that the form of the world-i.e., the totality of objects-determines the range of structures atomic states of affairs can have. So, for example-and speaking now in a way Wittgenstein would officially repudiate-there could be a 27 -termed relational atomic state of affairs only if there were 28 or more objects. (Here I assume that relations count as objects.) ${ }^{25}$ We are finally in a position to appreciate what it means to say that substance is 'form and content' $(2.024-5)$. Substance is 'form' because the objects that constitute it (2.021) also constitute the 'form' of the world (2.023); it is 'content'

(c) Blackwell Publishing Ltd. 2004 
because these same objects are the items of which atomic states of affairs are configurations.

\section{The Argument for Tractarian Substance}

Since substance, as the fixed form of the world, is the totality of what exists necessarily, what it is for the world to 'have substance' is for there to be necessarily existing things. But why should we suppose that there is any substance? What if everything there is were to be a complex of other things, and so destructible? Or what if the world were to contain simple objects every one of which was capable of passing out of existence without residue?

It is plausible to think that the second possibility is ruled out by various Tractarian commitments that are independent of the argument for substance. ${ }^{26}$ Suppose $a$ is a contingent simple. Then ' $a$ exists' must be a contingent proposition. But it cannot be an elementary proposition because it will be entailed by any elementary proposition containing ' $a$ ', and elementary propositions are logically independent (4.211). So ' $a$ exists' must be non-elementary, and so further analysable. And yet there would seem to be no satisfactory analysis of this proposition on the assumption that ' $a$ ' names a contingent simple-no analysis, that is to say, that is both intrinsically plausible and compatible with Tractarian principles. We cannot analyse ' $a$ exists' as the proposition ' $(\exists x) x=a^{\prime}$, for two reasons. First, Wittgenstein would reject this analysis on the grounds that it makes an ineliminable use of the identity sign (5.534). Secondly, even setting aside the first objection, the problem remains that given Wittgenstein's analysis of existential quantifications as disjunctions, the proposition ' $(\exists x) x=a^{\prime}$ would have to be analysed as the non-contingent proposition: ' $a=a \mathrm{v} a=b \mathrm{v} a=c \ldots$ '. Nor can we analyse ' $a$ exists' as: ' $\neg[\neg F a \& \neg G a \& \neg H a \ldots]^{\prime 27}$ - that is, as the negation of the conjunction of the negations of every elementary proposition involving ' $a$ '. For the proposition ' $\neg F a \& \neg G a \& \neg H a \ldots$.. could not be taken to mean ' $a$ does not exist', since by the lights of the Tractatus this proposition would show that $a$ does exist-or, more correctly, it would show something that one tries to put into words by saying ' $a$ exists'. So, pending an unforeseen satisfactory analysis of ' $a$ exists', this proposition must be analysed as a complex proposition not involving $a$. In other words, ' $a$ ' must be treated as an incomplete symbol. Or, to put the point in, so to speak, the material mode: the fact of $a^{\prime}$ s existence must be taken to consist in the fact that objects other than $a$ stand configured thus and so. But this would seem to entail that $a$ is not simple.

Plausibly, then, we may proceed on the assumption that the argument for substance is designed to exclude only the first possibility, that is to say, the possibility of a world in which the existence of each thing consists in the obtaining of facts about others, whose existence, in turn, consists in the obtaining of facts about still others, and so on. Such a world would fail to contain any necessary objects, because everything in it would be complex. In the argument

(C) Blackwell Publishing Ltd. 2004 
for substance proper (2.0211-2), Wittgenstein argues that such a world would be incompatible with the existence of thoughts.

The argument is presented in the form of a two-stage modus tollens, but for ease of exposition we may recast it in the form of a reductio:

Suppose, for reductio, that:

[1] There is no substance (that is, nothing exists in every possible world).

Then

[2] Everything exists contingently.

But then

[3] Whether a proposition has sense depends on whether another So proposition is true.

But

[4] We cannot draw up pictures of the world (true or false).

[5] We can draw up such pictures [the chief suppressed premise].

Contradiction.

So

[6] There is substance.

We face three main tasks in putting flesh on these bones. First, we must explain what it is for the sensefulness of one proposition to depend on the truth of another, and our explanation should make clear why the universal contingency of things should be thought to entail such a dependence (the step from [2] to [3]). Second, we must explain what it is to draw up a picture of the world (true or false)', and why the dependence of sensefulness on truth might be thought to imply that we cannot do so (the step from [3] to [4]). Finally, we must say why it might seem obvious that we can draw up such pictures. Our explanations, in order to amount to satisfying exegesis, need not make the argument come out sound, but they must explain why it might have once seemed compelling to Wittgenstein-or, at least, they must make clear why Wittgenstein, even if he saw the argument as ultimately nonsensical, might have regarded it as something his readers would have found compelling. For expository convenience I will focus on laying out the argument and postpone criticisms until section 6 .

\section{The Dependence of Sense on Truth}

Let us begin with the step that leads from [2] to [3]. What does it mean to say that 'whether a proposition had sense would depend on whether another was true'? At first blush, this seems to mean that a proposition, $p$, will have sense with respect to some possible circumstances-viz., those in which another proposition, $q$, is true-but not with respect to others-viz., those in which $q$ is false. But how should these 'circumstances' be understood? Are they the circumstances in which the sentence is uttered, or the circumstances relative to which its truth

(C) Blackwell Publishing Ltd. 2004 
value is evaluated? In other words, using the terminology made famous by David Kaplan, ${ }^{28}$ are they 'contexts of utterance' or 'circumstances of evaluation'? In order to explore the prospects of sympathetically reconstructing Wittgenstein's argument, we shall need to consider each possibility separately.

To begin with, let us suppose that the circumstances in question are contexts of utterance. This would furnish one natural model for understanding how one proposition's having a sense might depend on another's being true-or, at least it would do so if we were to understand a 'proposition' as a sentence with its linguistic meaning. For nowadays it is a commonplace to observe that some meaningful sentences may fail to express any thought (i.e. truth-evaluable sense) relative to some contexts of utterance. For example, pointing into the fog, I might utter the sentence 'That ship is listing to starboard', but since there is no ship near but only a dark cloud on the horizon, the demonstrative 'that ship' will refer to nothing, and my utterance, consequently, will express no thought. In such a case, whether the sentence I utter expresses a thought-and so, on one understanding of the phrase, 'has sense'-will depend on some contingent fact.

So far, so good: we have described what we might call 'a contextual dependence of sense on truth'. But how will this account apply to sentences containing names rather than demonstratives? The issue now becomes complicated, for we need to be clear whether we are considering ordinary names, such as 'Bush', which on the conception of the Tractatus are what Russell called 'incomplete symbols', ${ }^{29}$ and which are said to 'signify' complexes only by courtesy, or whether we are rather considering genuine, unanalysable (3.26) Tractarian names. In the former case, there is little reason to think that on Tractarian principles there would be a dependence of sensefulness on truth. For if I were to utter the sentence 'Vulcan is a planet', say, and were later to discover that there is no such planet, then on Tractarian principles I should have to say that my utterance expressed a false thought, rather than no thought at all: ${ }^{30}$

A proposition in which there is mention of a complex will not be nonsensical, if the complex does not exist, but simply false. (3.24) (my translation).

So let's suppose that the dependence of sense on truth is to be generated by the actual-world failure of reference of a semantically simple name. Since we have already ruled out contingent simples, this would be to suppose that a semantically simple name refers to a complex. Would a sentence whose only referring expressions were such names have a sense that was hostage to facts about the context of utterance? Again, the answer would seem to be: 'on Tractarian principles, no'. For even if we were to obtain the final analysis of some proposition and to assert the proposition in its fully analysed form, it is unclear that the sentence asserted could fail to express a thought. For it is natural to view Wittgenstein as a Millian about genuine names, as holding, that is to say, that all there is to the semantic content of a genuine name is its bearer (cf. 3.203). That being so, it is doubtful that we could make any sense of the possibility of one and

(C) Blackwell Publishing Ltd. 2004 
the same genuine name being uttered both in contexts in which it refers and in contexts in which it does not. For in the latter kind of context all that is utteredon Millian assumptions-is a meaningless string of phonemes, not a name-withits-linguistic-meaning. The assumption that we should understand Wittgenstein's implicit appeal to circumstances in terms of contexts of utterance, therefore, looks unpromising.

I take it that the more promising strategy is to assume that the circumstances in question are circumstances of evaluation. This suggestion faces an immediate difficulty, but it is one that points to a sympathetic reconstruction of the argument. On one way of developing the present idea, we would suppose that a proposition containing a semantically simple term, ' $a$ ', fails to have sense evaluated with respect to worlds at which $a$ does not exist. (Whether ' $F a$ ', say, has sense would thus depend on the truth of some proposition whose truth is equivalent to $a^{\prime}$ s existence). The immediate difficulty with this suggestion is that it is unclear whether we can make any sense of the idea of modal evaluation when what we are meant to be doing is not evaluating a sentence with sense for truth or falsehood relative to various worlds, but rather evaluating a sentence for sensefulness relative to these worlds. For it is doubtful that we have any conception of what it is to evaluate a sentence for sense with respect to a possible world if this is not to collapse into the idea, already canvassed and rejected, of considering whether an utterance of that sentence in that world would express a thought.

These reflections suggest that if our attempts sympathetically to reconstruct the argument for substance are not to founder, we must depart from the letter of Wittgenstein's text. I propose that we proceed as follows. Let us construe 'having sense' as a matter of having a truth value, ${ }^{31}$ and let us treat the question whether a proposition has sense with respect to some particular world as amounting to the question whether an interpreted sentence has a truth value with respect to that world. Then the inference from [2] to [3] would be an inference from the contingent existence of everything to the circumstance that every interpreted sentence lacks a truth-value with respect to at least one possible world. (Henceforth, I shall refer to this property of sentences as 'having a gappy modal profile'.)

But what assumption underwrites this inference? One natural thought is that it must rest on the assumption that an interpreted sentence containing a semantically simple singular term that fails to refer with respect to some particular world will lack a truth value with respect to that world. This assumption is controversial, ${ }^{32}$ but its acceptance leads to the following relatively satisfying reconstruction of steps [1] to [3] of the argument.

Background assumption: Every senseful proposition has a final analysis that contains only semantically simple referring expressions. ${ }^{33}$ Suppose [1] the world has no substance. Then [2] everything exists contingently (by our understanding of 'substance'). But then everything is complex (by the argument from Tractarian commitments against contingent simples). But then there must be names referring to complexes. (This is not an assumption Wittgenstein would himself endorse, but it is a consequence of the argument's reductio hypothesis.) It follows that, relative to circumstances of evaluation where the complex referred to by the

(c) Blackwell Publishing Ltd. 2004 
name 'A' does not exist, ' $F[A]$ ' is without truth value. So the 'sense' (i.e. truth valuedness) of ' $\mathrm{F}[\mathrm{A}]$ ' depends on the truth of another proposition, viz., the proposition whose truth constitutes the complex $\mathrm{A}$ as existing. (If $\mathrm{A}$ is the complex $[c R d]$ then the proposition will be the proposition that $c R d$.) The same reasoning can be run through for sentences containing an arbitrary number of names, so, in general, whether a proposition has a truth value depends on whether another proposition is true. So, assuming 'having a truth value' is a reasonable reconstruction of the notion of 'having sense', [3] is true.

One difficulty for this interpretation is that Tractatus 3.24 clearly suggests that if the complex entity, A, were not to exist, the proposition 'F[A]' would be false rather than, as the argument requires, without truth value. So the argument appears to assume the falsity of 3.24. But the difficulty is only apparent. It only goes to show that 3.24 belongs to a theory which assumes that the world does have substance. On the assumption that the world has substance, Wittgenstein can say that whenever 'names' occur that appear to mention complexes that is only because they are not, after all, genuine names. But on the assumption that the world has no substance, so that everything is complex, Wittgenstein can no longer say this. For now he must allow that the genuine names occurring in a proposition's final analysis do refer to complexes. So in the context of the assumption that every proposition has a final analysis, the reductio assumption of the argument for substance entails the falsity of 3.24. But since 3.24 is assumed to be false only in the context of a reductio argument, it is an assumption that Wittgenstein can himself consistently endorse. ${ }^{34}$

\section{Picturing the World (Truly or Falsely)}

Let us now consider the step that leads from [3] to [4]. ${ }^{35}$ Recall that, given my reconstruction of [3], this amounts to an inference from the supposition that every proposition would have a gappy modal profile to the conclusion that it would be impossible to 'draw up a picture of the world (true or false)'. I take the latter claim to amount simply to the idea that we could not formulate senseful propositions. So the starting premise of the argument is the unobjectionable claim that we can frame at least some genuine propositions. The inference from my reconstructed version of [3] to [4] would be immediate on the assumption that it is essential to a genuine proposition to have a gap-free modal profile. Wittgenstein does not formulate this assumption in so many words in the Tractatus, but it is plausibly implicit in what he says at 4.023 . This runs: 'The proposition determines reality to this extent, that one only needs to say "Yes" or "No" to it to make it agree with reality" (4.023). In explaining this remark to C. K. Ogden, Wittgenstein says: 'The meaning [of 4.023] should be that a proposition determines reality such that by merely affirming or denying it one can make it agree with reality. A prop[osition] can't entirely determine reality for it always can either be true or false; but it can ONLY be true or false. That means the prop[osition] determines reality so far that one only needs to say "yes" or "no" to

(c) Blackwell Publishing Ltd. 2004 
it, and nothing more, to make it agree with reality'. ${ }^{36}$ So, on the conception of the Tractatus, a (genuine) proposition, by its very nature, is guaranteed, whatever reality it may confront, to agree or disagree with that reality.

We might put his point in contemporary terms by saying that a proposition is by its very nature to be evaluated as true or false tertium non datur with respect to each possible world. This line of interpretation receives some support from Wittgenstein's image of a proposition as a line dividing logical space. 'The proposition', he says, 'reaches through the whole logical space' (3.42). I take this to mean that a proposition, by its very nature, effects an exhaustive and exclusive division of the set of possible states of affairs. The same idea receives further, though less immediate, support from a passage in the Philosophical Investigations, where Wittgenstein would seem to be criticizing this very conception:

The sense of a sentence-one would like to say-may, of course, leave this or that open, but the sentence must nevertheless have $a$ definite sense. An indeterminate [unbestimmter] sense- that would really not be a sense at all.-This is like: An indefinite boundary is not really a boundary at all. Here one thinks perhaps: if I say 'I have locked the man up fast in the room - there is only one door left open' - then I simply haven't locked him in at all; his being locked in is a sham. One would be inclined to say here 'You haven't done anything at all'. An enclosure with a hole in it is as good as none. But is that true? (Wittgenstein 2001: § 99).

The first sentence of this passage establishes the Tractatus as the target of the criticism that follows. It alludes to the following remark:

A proposition can, indeed, be an incomplete picture of a certain situation [Sachlage], but it is always a complete picture. (5.156)

This idea is elaborated in the Notebooks:

If a proposition tells us something, then it must be a picture of reality just as it is, and a complete picture at that-There will, of course, also be something that it does not say-but what it does say it says completely and it must admit of SHARP demarcation.

So a proposition may indeed be an incomplete picture of a certain fact, but it is ALWAYS a complete picture. ${ }^{37}$

A proposition's being $a$ complete picture consists in its saying something that admits of sharp demarcation. Although it may leave much unsaid, and so be an incomplete picture of a state of affairs-it might tell you that Bush is in town, without telling you exactly where he is-what a proposition does say must be 'complete', or sharply demarcated in the sense that the proposition specifies determinately which situations would, if they obtained, make it true and which situations would make it false. In the Notebooks Wittgenstein describes this idea as the thought that a proposition should have a clear sense:

C Blackwell Publishing Ltd. 2004 
If the proposition "The book is on the table" has a clear sense, I must whatever is the case, be able to say whether the proposition is true or false. (Wittgenstein 1979: 67, 20.6.15)

I take it that to have a 'complete' or 'sharply demarcated' sense and to have a 'clear' sense are just the same thing: ${ }^{38}$ both amount to having a gap-free modal profile. If this is correct, then the idea that it is essential to a genuine proposition-a proposition with sense-to have a gap-free modal profile is contained in the remark that:

Every proposition that has a sense has a COMPLETE sense ... (Wittgenstein, 1979: 61, 16.6.15)

Plausibly, it is just this notion of 'clarity' or 'completeness' to which Wittgenstein is referring at Philosophical Investigations $§ 99$ when he imagines his interlocutor insisting that 'an indeterminate sense would really be no sense at all'. However, we must be careful not to confuse the demand that a proposition should have a determinate (i.e., 'sharp', 'clear', or 'complete') sense in order to be a proposition at all, with the desideratum that a proposition should be determinate. For Wittgenstein, an indeterminate sense is no sense at all, but an indeterminate proposition is a senseful proposition, albeit one that stands in need of further analysis. This much is clear from the Tractatus's remark that:

[The fact] that a propositional element signifies a complex can be seen from an indeterminateness in the propositions in which it occurs. (3.24)

Because any senseful proposition that is not fully analysed will contain some incomplete symbols that 'signify' complexes, a proposition's indeterminateness should not be understood to preclude its sensefulness. The indeterminateness of a proposition merely signifies that it still contains incomplete symbols and so stands in need of further analysis if it is to be put into a form in which its inferential relations to other propositions are readily apparent.

So, to sum up: (i) an incomplete picture of a fact is, in effect, a proposition made true by more than one possible world; (ii) an indeterminate proposition is one that has a sense that is to some degree inperspicuously expressed; (iii) an indeterminate sense is no sense at all, and a proposition with an indeterminate sense-for example, a proposition containing a vague predicate-is no significant proposition.

The criticisms of Philosophical Investigations $\S 99$ are directed against (iii); and they are well taken. We are nowadays familiar with Wittgenstein's general point about boundaries. It is a commonplace to observe that although the border between, say, India and China is in some places vague, or disputed, it does not follow that there is no border at all. And, consequently, because Shanghai, say, is sufficiently far from the border, we can assert a true and substantive proposition by saying 'Shanghai is in China'.

(C) Blackwell Publishing Ltd. 2004 
The lesson of Philosophical Investigations § 99-namely, that an indeterminate sense is a sense for all that-is merely an application of this more general lesson about boundaries to the case of a senseful proposition conceived of as a line dividing logical space. ${ }^{39}$ It boils down to the point that a vague division of logical space is still a division. Even though the dividing line may itself have a widththe dimensions of which, owing to higher-order vagueness, will themselves be vague-some situations will fall clearly on one side of the line, some clearly on the other. Consequently, a proposition with an indeterminate sense will still have some use, since by asserting it we will be able to exclude some situation. Thus from the perspective of Wittgenstein's later philosophy, the proposition cannot be meaningless.

We are now in a position to summarize our reconstruction of the argument. Suppose, for reductio, that the world has no substance. Then everything exists contingently. But then every proposition (i.e., every interpreted sentence) will fail to have a truth value with respect to some possible world, since its final analysis will contain at least one semantically simple sign whose referent does not exist in that world. But it is essential to a proposition to have a gap-free modal profile. So it is not possible to formulate a senseful proposition. But we can formulate such propositions. So there is substance.

Before considering criticisms of this argument, I should briefly explain why I favour the present reconstruction over a possible rival that exploits much of the same interpretative framework. It would be possible to read the claim that the world has substance as saying not that necessary objects exist, but that all the simples there are exist necessarily. Wittgenstein could then be taken to be arguing that if this were not so-if, that is to say, some actual simples existed contingently, then one or more supposed proposition about how things actually stand would turn out to have a gappy modal profile, and so would not be a proposition at all. But then we could not frame a complete picture of the world, that is to say, we could not formulate a proposition that reports the obtaining of every actual fact.

I take it that, in addition to the unnaturalness of understanding the world's having no substance in terms of the idea that not all simples exist necessarily, the present suggestion suffers from its reliance on an implausibly strong premise. That we might some day form a complete description of the world might well be an assumption it is reasonable to accept for purposes of scientific inquiry, in the spirit in which one might accept a Kantian regulative principle; but it is far from being the intuitively obvious starting point that one might have hoped for in the present argument.

\section{Criticisms of the Argument}

The principal objections to the argument in its reconstructed form concern its two most controversial premises. The first states that it is essential to a proposition to have a gap-free modal profile. The second states that a proposition is neither true

(c) Blackwell Publishing Ltd. 2004 
nor false evaluated with respect to a possible world at which the referent of one or more of its names does not exist.

As we have seen, Wittgenstein was himself to raise an objection to the first premise. Briefly put, the objection holds that apparently meaningful sentences containing vague predicates constitute prima facie counterexamples. The second controversial premise also faces a counterexample. The problem is that some interpreted sentences would seem to demand to be evaluated as true with respect to worlds at which the referent of one or more of their names does not exist. Consider, for example, negative existentials. Since an utterance of, say, 'Bush might not have existed' expresses a truth, there is reason to assess 'Bush does not exist' as true with respect to worlds at which Bush does not exist. ${ }^{40}$ The example involves an ordinary proper name, but the point would apply equally to negative existentials containing the kinds of names countenanced in the argument for substance, namely, semantically simple signs that are supposed-under the reductio assumption-to refer to complexes.

We might try to side step this objection by taking the main premise of the argument to be just that we can grasp some atomic propositions. But even if we were to grant this assumption as plausible, further argument would be required to defend the assumption that atomic propositions are to be evaluated as without truth value (rather than as false) at worlds in which the referents of one or more of their contained names do not exist. ${ }^{41}$

A final objection was raised by Wittgenstein himself. In the Investigations, he was to question the assumption that every proposition has a sense given by its complete or 'final' analysis (see Wittgenstein 2001: §§ 60,63-4, and 91). So our supposition that what gets modally evaluated is a proposition in its final, fully analysed form might itself be questioned.

The first criticism on its own is decisive against the argument. But although the present reading involves attributing errors to Wittgenstein, it has the virtue of attributing to him errors he was later himself to recognize as such (in the case of the first and third objections), or points which were grasped with sufficient clarity to be recognized as controversial only decades after his death (in the case of the second). No one should be surprised that a train of reasoning as ambitious as the argument for substance should contain problems of this kind.

\section{Conclusion: Substance and Analysis}

According to the present interpretation, Wittgenstein's argument for substance is not an argument that every-or even any-proposition has a final analysis. For even if there are some necessarily existing objects, and semantically simple names referring to them, this would not guarantee that the analysis of any proposition will terminate. For it may be that a proposition has an analysis that produces at every stage apparent names that are further analysable, even though at some stages it also produces genuine unanalysable names.

(C) Blackwell Publishing Ltd. 2004 
What the argument purports to demonstrate, rather, is that one of the necessary preconditions for the analytic project is fulfilled. If there are necessary (hence simple) objects, then there will be items fit to be the referents of the simple signs presupposed as possible by the analytic project. But why does Wittgenstein take it to be obvious that in analysing propositions we shall eventually come upon simple signs (cf. 4.221)? And whence his confidence that every proposition has a unique final analysis (3.25)? The Tractatus is silent on these questions, but the Prototractatus is more forthcoming: 'The analysis of signs', Wittgenstein says, 'must come to an end at some point, because if signs are to express anything at all, meaning must belong to them in a way that is once and for all complete' (Wittgenstein 1971: 3.20102). Since it was omitted from the Tractatus, this remark must be treated with caution. Nonetheless, it remains our best clue to the thinking behind these Tractarian commitments. Wittgenstein's idea would seem to be that a complex sign does not have a meaning in isolation but always owes its meaning to the meaning of its analysis. If that is right, it follows that no senseful proposition can have an infinite analysis, on pain of some of its signs never acquiring a meaning. So, if there is sense, there must be simple signs. This, I believe, is the thought that lies behind the Tractatus's remark that 'The requirement that simple signs be possible is the requirement that sense be determinate' (3.23). Since an indeterminate sense is no sense at all, this entails that the demand for senseful propositions just is the demand for simple signs. ${ }^{42}$ The argument for substance aims to show-or, more carefully, to get the reader temporarily to acquiesce in the belief that-the demand for senseful propositions is also the demand for necessary, hence simple, objects to be the referents of these signs. I hope to have made it plausible that, while not ultimately successful, the argument is a remarkably sophisticated piece of reasoning, especially so, given the rudimentary understanding of the workings of modal evaluation that Wittgenstein had at his disposal. ${ }^{43}$

\author{
Ian Proops \\ Department of Philosophy \\ University of Michigan \\ 2215 Angell Hall \\ 435 South State Street \\ Ann Arbor MI 48109-1003 \\ USA \\ iproops@umich.edu
}

\title{
NOTES
}

${ }^{1}$ Wittgenstein, 1989a.

2 I take it that all sides in the recent debates about the 'New Wittgenstein' agree, or should agree, on this approach. Indeed, since on Cora Diamond's therapeutic reading as

(C) Blackwell Publishing Ltd. 2004 
presented in Diamond 1988, the Tractatus's apparent positions are supposed to have a powerful attraction-to strike us not just as senseful, but as true, and since the thesis of Tractarian atomism is one that few philosophers have in fact found antecedently plausible, one would have expected proponents of the therapeutic reading to be committed to finding an apparently cogent argument in this passage, whose apparent cogency would then constitute the illusion that Tractarian therapy is intended to dispel. (I am grateful to Jamie Tappenden for reminding me of this point).

${ }^{3}$ For a sense of the difficulties involved in answering this question see Kremer 2001 and, especially, Sullivan 2002.

${ }^{4}$ What follows makes no pretence to be an argument by elimination for the suggestion that Wittgenstein is alluding to Kant. But it strikes me that Locke's and Aristotle's notions are so deeply entrenched in the tradition that a word ought to be said about them. The suggestion that Wittgenstein's objects are 'very like' the Categories' notion of primary substance is found in Urmson 1966: 57.

${ }^{5}$ Aristotle 1991. vol. 1:4

${ }^{6}$ Ibid.

${ }^{7}$ For a convincing argument that this is not in fact Locke's view see Ayers 1993, volume 2 , chapters $1-5$.

${ }^{8}$ I take this formulation of the traditional conception from Ayers 1993, volume 2:52.

${ }^{9}$ Wittgenstein 1989b: 11. Cf. Wittgenstein 1970: 121.

${ }^{10}$ Fogelin, 1987: 10.

${ }^{11}$ Kant's additional remark that the quantity of substance neither increases nor diminishes is just a corollary of this claim.

12 Kant 1997.

${ }^{13}$ Both the Tractatus and the Prolegomena specifically discuss the example of oppositely handed gloves, and both consider the impossibility of superimposing one hand upon another. It is doubtful that Russell's discussion of incongruent counterparts in the Principles could have been the source for Wittgenstein's, since Russell merely quotes a passage from Kant's 1768 work Concerning the Ultimate Ground of the Differentiation of Directions in Space, which work mentions neither gloves nor the idea of superimposing one hand upon another (Russell 1903: § 214, fn*; cf. Kant 1992: 370-72). Nor do the other places in which Kant discusses incongruent counterparts-the Inaugural Dissertation of 1770 (Kant 1992: 396), and the Metaphysical Foundations of Natural Science of 1786 (Kant 2002: 197ff)—seem likely sources. Unlike the Prolegomena, which is a popular introduction to Kant's mature work, these works are relatively obscure, and neither of them makes any mention of oppositely handed gloves.

${ }^{14}$ Here I prefer Ogden's more literal rendering of 'das Feste' (Wittgenstein 1981) to Pears and McGuinness's 'the unalterable' (Wittgenstein 1961) for, as we shall see, the contrasting notion is not alteration, but existence change.

${ }^{15}$ Wittgenstein 1981.

16 This reasoning relies on a quite specific conception of a 'part' according to which it is necessary to a part of a thing that it could exist separately from the rest of it. Wittgenstein was later to emphasize the variety of notions of simplicity and complexity, and to reject any one notion as central. See Wittgenstein 2001: §§ 47ff.

${ }^{17}$ It is worth noting, in this connection, that one can use the adjectival participle 'bestehend' to mean 'prevailing' as, for example, in the phrase 'the laws prevailing since 1887' ('die seit 1887 bestehenden Gesetze'). Neil Tennant has pointed out to me that a further connotation of 'das Bestehende' is 'the constituting.' Wittgenstein's choice of terminology thus brings out the fact that objects play precisely the role one would expect from Kantian

(C) Blackwell Publishing Ltd. 2004 
'substance'. They make up the underlying, constituting stuff that endures through all existence changes.

18 Goldfarb 1997: 70.

19 See note 14 above.

${ }^{20}$ Goldfarb 1997: 70. Goldfarb attributes this suggestion to an unpublished manuscript of Thomas Ricketts.

${ }^{21}$ Goldfarb does not cite any texts that rule out an alternative conception of states of affairs according to which they can endure and recur, and so are appropriately expressed by propositions containing no time indexes. (For example, the apple's being on the table is a state of affairs that might obtain for five minutes and then cease to obtain.)

22 Russell 1981: 63. I am indebted to Jamie Tappenden for this observation.

23 Arguably, on Tractarian principles, it is incoherent to suppose that a state of affairs has a property. However, whether Goldfarb would wish to appeal to 'Tractarian principles' at this point of the supposed dialectic is unclear.

${ }^{24}$ I owe the idea that there is an allusion to Kant in the phrase 'empirical reality' to Peter Sullivan.

25 'Relations and properties, etc., are objects too.' (Notebooks entry for $16^{\text {th }}$ June, 1915; Wittgenstein 1979: 61). Cf. Wittgenstein 1989b: 120.

${ }_{26}$ The argument of this paragraph is indebted to an anonymous referee.

27 See Carruthers 1990: 94 for the suggestion that ' $a$ does not exist' should be analysed as ' $\neg F a$ \& $\neg G a$ \& $\neg H a \ldots$..'

28 See 'Demonstratives' in Kaplan 1989: 481 - 563.

29 Signs, that is to say, which have no meaning in isolation, but which are eliminable from the contexts in which they occur by paraphrase (cf. Russell 1990: 66). A paradigm example would be the expression 'the $\mathrm{F}^{\prime}$, which is shown to be eliminable from the contexts in which it occurs by means of the contextual definitions that comprise Russell's theory of descriptions.

${ }^{30}$ In the present context we are operating under the assumption that the circumstance indicated by the phrase 'if the complex does not exist' at 3.24 is a context of utterance.

${ }^{31}$ One might find some precedent for this idea in the remark from the Notes on Logic that 'a proposition has two poles, corresponding to the case of its truth and the case of its falsehood. We call this the sense of a proposition.' (Wittgenstein 1979: 99). I take it that Wittgenstein means that having sense is a matter of having these two truth poles. It might be objected that this view is incompatible with Wittgenstein's view of tautologies and contradictions as without sense even thought they are, respectively, true and false. However, it is unclear how much weight should be given to this point, for 4.06 and 4.462 together imply that tautologies and contradictions cannot, strictly speaking, be true or false.

${ }^{32}$ See note 41 below.

33 I discuss texts supporting an attribution of this view to Wittgenstein in the concluding section. Recall that for Wittgenstein the logical connectives do not 'represent' (4.0312).

${ }^{34}$ The solution to the present difficulty is owed, in its essentials, to David Pears. See Pears, 1987: 78.

${ }^{35}$ In seeing [3] as a premise that is not simply assumed, but which needs to be argued for, my interpretation departs from Pears's (cf. Pears 1987: 66).

36 Wittgenstein 1973: 27.

37 Wittgenstein 1979: 61; cf.: 63.

38 The variation in terminology may well reflect the different intuitive pictures one might use to convey the idea of a gappy modal profile. According to one picture, some 
situations (points in logical space) fail to fall determinately on one or other side of a line partially dividing logical space because the line has breadth; according to another picture, the line is breadthless, but contains gaps. In the former case one might naturally say that the proposition's sense is not 'clear' or 'sharply demarcated,' in the latter, that it is not 'complete.'

39 Another application is Wittgenstein's point against Frege at Wittgenstein 2001: § 77, namely, that we can make claims that are true or false using concepts whose extensionsand indeed intensions (cf. Wittgenstein 2001: § 80)—are not precisely fixed. For Frege's opposite view, see Frege 1962, vol. 2, § 56.

40 See Salmon 1981: $34-41$.

${ }^{41}$ On the other hand, the assumption that an atomic proposition is false evaluated with respect to worlds at which the referent of one of its names does not exist faces difficulties of its own. Suppose the world $w$ consists only of blue things. Suppose that $a$ does not exist at $w$ and that ' $a$ is blue' is atomic. Then, on this assumption, ' $a$ is blue' will be false at $w$. But then ' $a$ is not blue' will be true at $w$, and so ' $\exists x$ ( $x$ is not blue)' will be true at $w$, contrary to our supposition. This shows that in order to defend the falsehood assumption either one's truth definition will need to incorporate a non-standard clause for negation or one will have to adopt the rules of a free logic. (I am indebted to Peter Pagin for this observation.)

${ }^{42}$ It is no accident, I think, that the forerunner of Tractatus 3.23 in the Prototractatus immediately precedes Wittgenstein 1971: 3.20102, which is quoted above.

${ }^{43}$ My thanks to Jason Stanley, Jessica Wilson, Neil Tennant, William Taschek, Louise Antony, Benj Hellie, Peter Ludlow, Jim Joyce, John Halpin, Kathrin Gluer-Pagin, Åsa Wikforss, Peter Pagin, James Conant, and Peter Sullivan. Special thanks to Jamie Tappenden, Joshua Brown, and Stacie Friend for extended conversations about this material and for commenting on multiple drafts. Earlier versions of this paper were presented as talks at Ohio State University, Oakland University, the University of Stockholm, and the University of Uppsala. I am grateful to the audiences on each occasion for their helpful comments and questions. The final version benefited from the most helpful remarks of two anonymous referees.

\section{REFERENCES}

Ayers, Michael. (1993 [1991]), Locke: Epistemology and Ontology. London: Routledge.

Barnes, Jonathan (ed.) (1991). The Complete Works of Aristotle, The Revised Oxford Translation, ed. Jonathan Barnes. New Jersey: Princeton University Press.

Carruthers, P. (1990), The Metaphysics of the Tractatus. Cambridge: Cambridge University Press.

Diamond, C. (1988), 'Throwing Away the Ladder: How to Read the Tractatus', Philosophy 63, reprinted with a postscript in Diamond 1991:179-204.

- (1991), The Realistic Spirit. Cambridge: MIT Press.

Fogelin, R. (1987 [1976]), Wittgenstein. London: Routledge and Kegan Paul Inc.

Frege, G. (1962 [1893, 1903]), Grundgesetze der Arithmetik. Darmstadt and Hildesheim: Olms.

Goldfarb, W. (1997), 'Metaphysics and Nonsense: On Cora Diamond's The Realistic Spirit', Journal of Philosophical Research, 22, 57-73.

Kant, I. (1992), The Cambridge Edition of the Works of Immanuel Kant, Theoretical Philosophy, 1755-1770, trans. and ed. David Walford. Cambridge: Cambridge University Press.

(C) Blackwell Publishing Ltd. 2004 
(1997 [1783]), Prolegomena to Any Future Metaphysics, trans. and ed. Gary Hatfield. Cambridge: Cambridge University Press.

(2002), The Cambridge Edition of the Works of Immanuel Kant, Theoretical Philosophy after 1781, ed. Henry Allison and Peter Heath, trans. Gary Hatfield, Michael Friedman, Henry Allison and Peter Heath. Cambridge: Cambridge University Press.

Kaplan, David (1989), 'Demonstratives' in Themes from Kaplan. Oxford: Oxford University Press.

Kremer, M. (2001), 'The Purpose of Tractarian Nonsense', Nô̂s, 35: 39-73.

Pears, D. (1989 [1987]), The False Prison, vol. 1, Oxford: Oxford University Press.

Russell, B. (1981 [1917]), 'Mathematics and the Metaphysicians', in Mysticism and Logic

New Jersey: Barnes and Noble, 1981.

— and Whitehead, A. N. (1990 [1910-1913]), Principa Mathematica to *56. Cambridge:

Cambridge University Press.

- (1996 [1903]), The Principles of Mathematics. London: Allen and Unwin.

Salmon, N. (1981), Reference and Essence. Princeton: Princeton University Press.

Sullivan, P. (2002), 'On Trying to be Resolute: A Response to Kremer on the Tractatus', European Journal of Philosophy, 10: 43-78.

Urmson, J. O. (1966 [1956]), Philosophical Analysis. Oxford: Oxford University Press.

Wittgenstein, Ludwig (1961), Tractatus Logico-Philosophicus, trans. D. F. Pears and B. McGuinness. London: Routledge and Kegan Paul Ltd.

- (1970), Eine Philosophische Betrachtung, edited by Rush Rhees, in Ludwig Wittgenstein:

Schriften 5. Frankfurt am Main: Suhrkamp.

(1971), Prototractatus: An Early Version of Tractatus Logico-Philosophicus, by Ludwig

Wittgenstein, eds. B. F. McGuinness, T. Nyberg and G. H. von Wright. London:

Routledge and Kegan Paul Ltd.

- (1973), Letters to C. K. Ogden with comments on the English Translation of the Tractatus Logico-Philosophicus, ed. G. H. von Wright. Oxford: Blackwell.

_ (1979 [1961]), Notebooks, 1914-1916, eds. G. H. von Wright and G. E. M. Anscombe, trans. G. E. M. Anscombe. Oxford: Blackwell.

— (1981 [1922]), Tractatus Logico-Philosophicus, trans. C. K. Ogden. London: Routledge and Kegan Paul Ltd.

(1989a), Logisch-Philosophische Abhandlung: kritische Edition, eds. B. McGuinness and J. Schulte. Frankfurt am Main: Suhrkamp.

— (1989b), Wittgenstein's Lectures Cambridge, 1930-32, From the notes of John King and

Desmond Lee, Desmond Lee, Midway reprint. Chicago: University of Chicago Press.

— (2001 [1953]), ed. Philosophical Investigations, 3rd edn. Oxford: Blackwell. 